bacillus, as might occur when the organism has multiplied in contaminated food. Travellers should be warned not to trust local water supplies and should drink wine or bottled mineral water with their meals. If they wish to use tap-water for anything but washing in areas of high risk they should carry water-sterilizing tablets, which can be bought cheaply in this country. As a general rule one of these tablets will sterilize a litre of water in about 30 minutes. Soft-skinned fruits can be made safer by being immersed for 30 minutes in water containing four sterilizing tablets to the litre. Cold foods and salads should be avoided, as should eating in general in villages. These precautions will probably reduce the risk of the tourist's contracting not only typhoid and paratyphoid fevers but also the enteritis which so commonly afflicts them on arrival in these countries.

Chloramphenicol is effective in the treatment of typhoid fever. It has reduced the mortality from about $10 \%$ to $1 \%$ or less, and shortens the duration of the illness. But the longer the delay in diagnosis the greater the risk to the patient from the lack of use of the drug. Some discussion of the early diagnestic features of the disease is given in an article below (page 608). Though premonitory symptoms may develop while the tourist is still abroad, the onset of typhoid fever usually occurs after his return to this country. Consequently, in the case of persons returning from areas where its incidence is high the possibility of the disease must be considered from the first day onwards in any pyrexial illness. If this is borne in mind, unnecessarily prolonged illness is avoided and the prognosis of the disease improved.

"Holiday typhoid" puts at risk persons who, having returned home, may be widely scattered over the country. In this respect the rapid exchange of information between medical officers of health helps to define the extent of an outbreak. The Department of Health and Social Security usually receives early information of cases and disseminates it. Travel agents are anxious to co-operate and will supply nominal rolls of persons in their parties. The availability of this information helps both the early recognition of cases and the investigation of contacts. This may be specially important if a person at risk is employed in the manufacture or handling of food.

In the case of an outbreak in a holiday resort which has probably been caused by an infected meal or by a discrete period of contamination of a water supply, the dates between which the incident has occurred can be estimated by determining the earliest date of departure and the latest date of arrival of cases in the outbreak. Patients will often volunteer the information that they and others in their party had attacks of vomiting or diarrhoea, and this may be valuable in arriving at possible dates of infection and in the exploration of the outbreak. Cultures of the typhoid bacillus should be sent to the Enteric Reference Laboratory, Colindale, London, for phage-typing as soon as possible after isolation. All cultures in an outbreak belong to the same phage-type. The rapid dispatch of cultures for phage-typing, as well as speeding up information on whether they are epidemiologically uniform, may give early warning of the existence of an outbreak.

Despite the publicity on the recent cases through the media of mass communication it should be emphasized that the total number is not large. However, typhoid fever has become news of recent years, largely because of the Zermatt and Aberdeen epidemics, and a good deal of misconception has arisen on the subject of its infectivity. It is a communicable but not a contagious disease. Infection does not occur unless the typhoid bacillus is ingested. Thus the disease does not spread with the freedom of smallpox, and the cases are usually limited to those who have been infected by the primary source. Secondary cases are relatively rare, and there is no risk of general spread. Though it must always be taken seriously, therefore, there is no justification for sensational reporting on typhoid fever as if it were the plague.

\section{M.R.C.P. (U.K.)}

To the foreign observer Britain's multiplicity of medical qualifications is confusing, even slightly comic. For his part the native of these shores must sometimes wonder whether the jungle of degrees, doctorates, masterships, and diplomas is not just a device for enriching the coffers of examining bodies. Some simplification has long been overdue, and the announcement last week about the M.R.C.P. examination by the presidents of the Royal Colleges of Physicians in London, Edinburgh, and Glasgow (page 663) is welcome.

The imminence of vocational registration and Common Market possibilities have made critical scrutiny of all higher qualifications imperative. Perhaps most in need of rationalization have been the higher diplomas offered by the Royal Colleges in medicine and surgery. Crucial years and much money could be spent in obtaining them, and at the end there lurked the suspicion that in the race for jobs-at least in some areas-the holder of more than one fellowship or membership had an advantage over the applicant with only one. The process of reform and collaboration which the surgical colleges began as long ago as $1955^{1}$ is gathering. momentum. In October 1968 the Royal Colleges of Physicians of London and Edinburgh and the Royal College: of Physicians and Surgeons of Glasgow established a common Part I examination for their memberships, it being their ultimate aim $^{2}$ to discourage candidates from acquiring by examination the membership of more than one college.

From October this year candidates successful in the membership examination of any of the three Royal Colleges of Physicians will be awarded the M.R.C.P. (U.K.). This will entitle them to certain privileges in each of the colleges, but. not of itself to membership of an individual college. This. will cease to be obtainable by examination. A holder of the M.R.C.P. (U.K.) will, however, be able to apply for such closer association with a particular college as its constitution allows. For the present each college will continue with its. own Part II examination, though talks are proceeding with a. view to getting a common examination.

What could so easily undermine the colleges' wholly admirable purpose is any real variation in standard of the three examinations leading to the common diploma. The colleges: themselves regard the present Part II examinations as of equal standard, and a substantial interchange of examiners: has been arranged to help keep them that way. But the acid test will be what the candidates do. It would be a sad spectacle, and bring the U.K. diploma into disrepute, if at each examination a flood of candidates descends on one college and only a trickle goes to the otiner two. The sooner therefore that a common Part II examination can be achieved the better.

British Medical Journal, 1969, 1, 502.

British Medical fournal, 1968, 1, 849.

Report of the Royal Commission on Medical Education, 1965-68 1968. London, H.M.S.O

- British Medical fournal, 1969, 1, 569. 
But these changes, beneficial in themselves, leave unanswered the main question: How relevant is the M.R.C.P. examination to the selection of future physicians? The Royal Commission on Medical Education ${ }^{3}$ had no use for "a single major 'pass or fail' examination" for assessing performance in its three-year period of general professional training. It preferred reports from supervisors and chiefs of units, and thought that satisfactory completion of this training should be regarded as evidence of eligibility for college memberships. The Royal College of Physicians of London, however, argues ${ }^{4}$ that there is still a place for a standardized test of sound basic knowledge of medicine and fitness to pursue further specialized training, and that candidates would themselves want an unbiased assessment such as a common M.R.C.P. could provide. This is an argument that needs settling before the new diploma becomes entrenched.

\section{Spotting Typhoid}

British holiday-makers returning from abroad this week have been met by newspaper placards of typhoid outbreaks. Family doctors will need to be alert to the possibility of typhoid among their patients, though its early recognition is by no means easy.

Typhoid is a great mimic, and any continuing fever should arouse suspicion. Indeed, "typhoid or paratyphoid fever should be considered as a possible diagnosis in any person who has had unexplained pyrexia for three days or more ; if the patient has recently been abroad it should be considered from the first day of illness." If the diagnosis is suspected, the medical officer of health should be consulted by telephone; blood should be taken for culture and Widal testing at once. Specimens of faeces and urine should also be taken for culture ; contrary to general opinion, based on earlier bacteriological techniques, these are usually positive in the first week of illness.

During the first week there are no specific diagnostic features. Usually there is a rising fever, with morning remissions, a pulse rate of $80-90$, and progressive lassitude and malaise. The tongue is coated, there may be sordes, and the skin is dry and musty. The abdomen is slightly tender, with a doughy feel, and the patient may be constipated at this stage. Often there is a mild bronchitis.

In the second week the clinical picture becomes clearer, particularly if the classical scanty rose spots are found after the seventh day. The fever reaches its height at this stage ; toxaemia is marked, and the soft, tender spleen may become palpable. The abdomen becomes distended, and the stools may become loose, but the patient may be constipated. By the third week the disease is well advanced.

By the second week of the illness there should be no difficulty in confirming the diagnosis bacteriologically by culture of faeces and urine; in a febrile patient the organism may still be present in the bloodstream. The Widal test is positive, but its interpretation may be difficult in a patient who has had T.A.B. vaccine, so it is important to do a Widal test as early as possible in the illness so that any later rise in titre may be detected.

\footnotetext{
1 Typhoid and Paratyphoid Fevers. Prepared by the Standing Medical Advisory Committee for the Central Health Services Council and Ministry of Health. London, H.M.S.O. 1965.
}

\section{Success and Failure}

Until lately doctors' failures to cure their patients caused more concern than their therapeutic successes. But the efficacy of some of the new methods of resuscitation, repair, and replacement of tissues or whole organs is presenting the medical profession with dilemmas much sharper than were known to earlier generations. Success is beginning to provoke as much thought as failure. A doctor's natural reaction to do all he can to preserve his patient's life is stilled only by the firm belief that it will be a fruitless interference likely to bring his patient nothing but further suffering. A painful example of the failure to let nature take its course was recorded last year by W. St. C. Symmers, ${ }^{1}$ and W. Ritchie Russell $^{2}$ added that it was but an extreme example of what may be observed in the wards of every hospital in the country.

But what is nature's course ? And when should the doctor refrain from interfering with it ? Circumstances must differ in individual cases, and in none can the problem be more acute than when the patient is a newborn baby who at best is faced with a life of gross disability, perhaps mental as well as physical. J. S. Lawson, ${ }^{3}$ of Melbourne, has discussed the ethical problems in the management of severely ill, handicapped babies. He reviews 20 with such conditions as severe spina bifida with paraplegia who develop meningitis ; severe mental defect with a surgically remedial anomaly such as intestinal obstruction; and combinations of brain damage due to birth injury with spina bifida and meningitis. Of the treatment of these babies he asks four "important ethical questions":

(1) Should life-saving measures be instituted ?

(2) Should this decision be made by the doctor alone ?

(3) Should the decision be made by the doctor after discussion with the parents?

(4) Should the decision be left mainly to the parents ?

The author recognizes the uncertainty a doctor must feel about the validity of the replies parents may give when he tries to elicit their views, and so their true feelings " had to be interpreted from flexible interviews designed to allow the parents to discuss freely their point of view." He found that in all cases but one (from which conclusions could not be drawn) the parents hoped for "an early peaceful death" of their infant. But discussing with 13 sets of parents the question of carrying out life-saving treatment he found that five favoured and eight opposed active intervention. Four years after he had initially seen them Lawson again interviewed six sets of parents. They then expressed similar feelings to what they had before and "were pleased their infants had died." Summarizing the parents' opinions in general, Lawson says it would seem that most would prefer their infant to die quickly and peacefully rather than live with severe handicaps, but they would rather not accept the responsibility for deciding their infant's fate. In considering the course the doctor should take, he writes that " in my opinion parents of these infants should not participate in the actual decision whether or not to implement treatment." With this view most doctors would agree.

While the complexity of treatment available today can make the taking of a correct clinical decision worrying enough, its efficacy can add to the doctor's anxieties rather than dispel them. To find a course that is ethical and humane as well as medically sound is part of the doctor's

\footnotetext{
Symmers, W. St. C., Sen., British Medical fournal, 1968, 1, 442.

2 Russell, W. R., British Medical fournal, 1968, 1, 576.

Lawson, J. S., Australian Paediatric fournal, 1968, 4, 186.
} 